\title{
DIANA EN PALACIO: EL NOMBRE COMO FORJADOR DE UN DESTINO
}

\author{
Rafael Massanet Rodríguez \\ Universitat de les Illes Balears - IEHM \\ r.massanet@uib.es
}

\section{El DESTINO ESTÁ EN EL NOMBRE}

\begin{abstract}
ristóteles, en el capítulo noveno de su Poética, habla sobre los «nombres potenciales» $»^{1}$, aquellos que determinan unas cualidades y características 1 propias del personaje al que designan. Morley, a raíz de esta cuestión, se preguntó lo siguiente: «In the comedia, do certain given names connote certain stations in life or certain callings?» (1959: 222). Frente a la idea del nombre literario como simple etiqueta carente de significado (Mill, 2002), encontramos la teoría de la hipersemanticidad²:
\end{abstract}

Aceptar la idea de un nombre propio carente de contenido, significaría reducir el análisis de los nombres literarios a los aspectos meramente formales o, en el mejor caso, limitar la investigación semántica a los nombres naturalmente motivados. Un rápido examen de algunas de las obras más relevantes de la literatura universal prueba indudablemente el hecho de que en un texto de ficción los nombres propios son altamente significativos y siempre cumplen una finalidad poética (Ionescu, 1993: 305).

Sin embargo, las pesquisas de Morley no prosperaron más allá de extensos listados que resultan de utilidad como documentación inventarial y punto de partida para estudios como el que nos proponemos abordar. Estos trabajos se centran

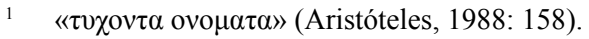

2 Barthes (1967) desarrolla esta teoría en relación a la obra de Proust, En busca del tiempo perdido. Establece tres grandes poderes que presenta el nombre propio: el de esencializar, el de citar y el de exploración.
}

Edad de Oro, XXXIX (2020), pp. 253-274, ISSN: 0212-0429 - ISSNe: 2605-3314 
en demostrar una correlación entre los nombres propios y las diferentes clases sociales a las que pertenecen los personajes de cada una de las comedias.

El nombre no se establece al azar, sino que impregna al personaje con una serie de características determinadas por su etimología y origen:

Se asume, pues, que el nombre posee un numen sagrado y ejerce un mágico poder sobre quien lo lleva [...] Aunque sean los autores cómicos, sobre todo, los que hayan sacado un mayor partido literario de la relación que los nombres guardan con las cosas que designan, no obstante, donde la alianza entre nomen y numen se halla mejor reflejada desde un punto de vista antropológico es en la tradición teológica, y bastará recordar los muchísimos personajes bíblicos cuyos actos quedan justificados por los nombres propios que llevan (y viceversa, cuyos nombres, lejos de ser arbitrarios, son adjudicados a modo de premonición de lo que va a pasar) (López López, 1989: 6-7).

Crea un antecedente ante el público, quien, al conocer el nombre de un personaje de la obra a la que asiste, establecerá un horizonte de expectativas. Sin embargo, tal como señala Meunier: «Leer el nombre propio no trastorna la comprensión de la comedia, pero sí permite profundizar en la construcción de su universo mental y poético» $(2015: 115)$.

Entre todo el compendio de textos teatrales áureos, debemos trazar una diferenciación entre las obras de asunto histórico y mitológico, y el resto. Entre las primeras encontraríamos nombres fijados en torno a personajes conocidos, en los que la capacidad inventiva del autor no puede desviarse de las líneas del relato ya establecido:

Some of the names are fixed by history or legend - Greek in El Aquiles, biblical in La mejor espigadera, La mujer que manda en casa and La venganza de Tamar, historical in La vida de Herodes. For such names Tirso had no choice, but there seemed no practical way of excluding them from a study. The line between invention and tradition is too hard to draw (Morley, 1959: 222).

Sin embargo, ¿qué ocurre cuando se designa a una persona con un nombre que remite a alguna de estas figuras pero que, en apariencia, no posee relación alguna? La respuesta se rige por el mismo principio que en el primer grupo. Los personajes adquieren rasgos en su comportamiento que parten de las asociaciones que se establece con la etimología del nombre asignado: «La literatura moderna [...] se vio en alguna de sus épocas especialmente marcada por la idea de que los nombres propios contienen la clave del destino de las personas, tanto el de aquellas que los llevan como el de sus más inmediatos semejantes» (López López, 1989: 7).

Morley y Tyler, en su estudio sobre Los nombres de los personajes en las comedias de Lope de Vega, presentan un extenso listado en el que clasifican el uso que hace el Fénix de los Ingenios de los nombres de sus personajes en relación 
con la posición social y su función dentro de la obra ${ }^{3}$. Nombres como Alejandro, Diego o Enrique se reservan para personajes nobles, mientras que quien fuera bautizado como Tirso, Gil o Belardo nunca alcanzarían ese estado, siendo relegados a las clases bajas, como pastores, graciosos o villanos. Esta situación indica una clara tipología distinguida desde la propia nomenclatura del personaje, que influirá de manera directa en el imaginario colectivo del público:

La relación «nombre/cosa», que al principio filosóficamente se nos insinuaba bajo apariencia de relación «manera de ser/destino», tiene su paralelo filológico en el binomio «nombre/función», esto es, en la congruencia —o no- entre lo que el nombre significa y el papel o tipo que el personaje que lo lleva incorpora (López López, 1989: 11).

La sola mención del nombre provoca que el público identifique al personaje con un determinado papel, e, incluso si este se presentara bajo un disfraz, el nombre desvelaría para el público su posible realidad:

Se desemboca así en nombres o categorías de nombres ligados a tipos literarios más que sociales: la dueña, el gracioso, etc [...] Como fácilmente se observa, este tipo de nombres cómicos no se limitan a caracterizar la función dramática del portador, sino que implican además alusiones individuales [...] La jerarquía de unas y otras connotaciones dependerá de cada caso particular (Arellano, 1986: 56).

Hay que tener presente que el universo dramático áureo es tan amplio que el estudio de un único nombre en toda la producción del periodo es una tarea titánica, que puede no darnos ningún tipo de resultado. Como señala Hoek: «plusieurs types de remotivation peuvent jouer à la fois dans un seul nom prope, l'une entraînant l'autre» (1981: 237). El valor de un nombre dependerá en última instancia del género literario, de la clase del discurso poético, de la época o de la intención final del autor.

Con esto en cuenta, podemos afirmar que los nombres variarán ligeramente de referente, o presentarán características sutilmente amplificadas, dependiendo de la tipología de la comedia en que aparezcan. Así ocurre con el nombre de Diana en las comedias tradicionalmente conocidas como palatinas. Mientras que en una comedia de corte mitológico aparecerá sobre las tablas la propia diosa latina, haciendo gala de los motivos que la caracterizan, en comedias de corte cómico no encontraremos dioses, sino hombres. La cuestión radica, sin embargo,

3 Morley también llevó a cabo un estudio acerca de los nombres de los personajes en las comedias de Tirso de Molina. Sin embargo, es más breve y sesgado y, aparte de un extenso listado, no aporta un estudio detallado que relacione los nombres con las clases sociales ni con el oficio que desempeñan. 
en el grado de identificación de caracteres que se pueden vincular con la supuesta fuente clásica de la que bebe.

\section{Definiendo la escena palatina}

Las características de la comedia palatina se han fijado a lo largo del tiempo desde que Weber (1977) y Wardropper (1978) establecieran una diferenciación tipológica y acuñaran el término (Weber, 1975). Posteriormente, autores como Vitse (1988) u Oleza (1997) terminaron de perfilar las coordenadas exactas a través de las que poder clasificar las distintas obras producidas durante este siglo.

Bances Candamo, en su Teatro de los teatros de los pasados y presentes siglos, preceptiva inacabada, establece la primera diferencia entre las comedias modernas frente a las antiguas, que divide entre comedias historiales y comedias amatorias, subdividiéndolas a su vez entre las de capa y espada y las de fábrica. Es precisamente la definición de estas últimas las que más se asemejan al concepto actual de comedia palatina:

Las de fábrica son aquellas que llevan algún particular intento que probar con el suceso, y sus personajes son reyes, príncipes, generales, duques, etc., y personas preeminentes sin nombre determinado y conocido en las historias, cuyo artificio consiste en varios acasos de la Fortuna, largas peregrinaciones, duelos de gran fama, altas conquistas, elevados amores y, en fin, sucesos extraños, y más altos y peregrinos que aquellos que suceden en los lances que, poco ha, llamé caseros (1970: 33).

La perspectiva desde la que escribe Bances Candamo nos permite interpretar sus palabras como un análisis de la evolución de los géneros dramáticos del siglo XVII ${ }^{4}$. Más allá de las descripciones literarias que puedan proporcionar los distintos autores de la época, debemos atender los rasgos principales que la crítica ha ido estableciendo desde una posición alejada temporalmente de la concepción de esta clase de comedias. Los rasgos imprescindibles para considerarlas pertenecientes al género palatino son los siguientes:

La localización espacial no española, a lo que se suma una imprecisión temporal. La lejanía de la esfera conocida permite al autor crear situaciones verosímiles, sin que los espectadores tengan que sentir una identificación directa con lo representado. Al desarrollarse la acción en un país exótico y en un tiempo indeterminado, el público no exigirá el cumplimiento riguroso de la verosimilitud

$4 \quad$ Estos rasgos definitorios ya estaban presentes en la escena española en manos de dramaturgos del último cuarto del siglo xvI, como Cristóbal de Virués, Jerónimo Bermúdez, Morales, Lupercio Leonardo de Argensola o Juan de la Cueva. 
respecto al entorno conocido. Se establece un pacto entre espectador y autor por el que es capaz de aceptar lo representado, aunque no se ajuste a la realidad. Esta lejanía supone una libertad en la creación del dramaturgo, pudiendo situar a sus personajes en situaciones que, en géneros más cercanos a una esfera histórica, sería imposible. El dramaturgo logra escapar del estereotipo temático del periodo, al superar el límite espaciotemporal, y logra ofrecer asuntos de carácter extraordinario sin enfrentarse de manera directa a la sociedad establecida del momento.

No obstante, siempre deben aparecer elementos reconocibles para el espectador, ya sea mediante personajes de origen español, ya mediante la mención de topónimos o elementos de su cultura. Hay que tener en cuenta que debe producirse una conexión entre el espectador y la obra representada. Lo externo a su esfera de conocimiento aleja el interés que pueda tener, por lo que es necesario que se produzca una identificación entre quien ve y lo que ve:

Llamamos así a la relación personal, consciente o inconsciente, que establece el espectador con las vivencias de los personajes. La razón principal por la que una historia resulta interesante al público reside en que su contenido conecta en algún aspecto con su vida, aunque solo sea de forma imaginaria, de alguna manera enlaza lo que pasa en escena con sus propias luchas, deseos y conflictos (Alonso de Santos, 2012: 190).

Otra de las características es la fantasía en este género de comedias, alejándose de la esfera cotidiana:

Las comedias que no se desarrollan en el «aquí y ahora», las que se basan bien en novelle italianas, bien en la libre imaginación del dramaturgo. Este género de comedia apenas se propone reflejar la realidad observable y tangible del mundo del espectador. Fantasioso o novelesco, es de ficción en grado sumo (Wardropper, 1978: 209-210).

Junto al alejamiento espaciotemporal es lo que permite que las tramas puedan ser aceptadas entre el público como verosímiles. No obstante, la localización espacial no española y la imprecisión temporal no constituyen todos los elementos que configuran la comedia palatina. Oleza señaló un detalle muy importante que, en muchas ocasiones, se ha pasado por alto, como es la ocultación, elemento imprescindible para el enredo: «Episodio de ocultación - voluntaria o involuntaria - de la identidad, que tiene por origen la desestabilización del orden justo (social, amoroso, moral...) y por punto final el restablecimiento del orden» (Oleza, 1997: 236). No debemos considerarlo tan solo como el recurso del disfraz físico, sino también todos aquellos hechos que provoquen que las intenciones del personaje queden ocultas para el resto, tanto para alguien concreto como para un grupo de individuos. Con esto podemos entender lo que Béziat (1996) definió 
como «silencio», extendiendo a cualquier discurso que no necesariamente sea expresado verbalmente.

Vitse se encarga de señalar el componente sociodramático que las comedias palatinas incorporan, poniendo en contacto personajes de distinto nivel social, difuminando las fronteras que se encuentran entre ellos, situación que no se podría dar fuera del mundo teatral:

Un elenco de personajes que pertenecen, por una parte, a la alta nobleza (rey, príncipes y señorías), y, por otra, a categorías subalternas (secretarios, villanos...) y cuyo distanciamiento social, al parecer insalvable, sufre un proceso (logrado o no) de reducción, a través de las complejas figuras del desprecio y de la correspondencia en el amor (en toda la polisemia de la palabra) (Vitse, 1988: 557).

La comedia palatina aborda asuntos de la vida de los personajes que orbitan en torno al palacio y su séquito, espacios y personajes alejados del público que asistía a las representaciones. Se produce, por tanto, un distanciamiento de lo cotidiano, entrando en el terreno de lo fantástico, aspecto ya mencionado. Por otra parte, debido al alto rango social de los personajes se producirá un fuerte contraste cuando tengan que relacionarse con sus subalternos, dando lugar al humor, rasgo que se encarga de señalar Vitse como elemento indispensable para considerar una comedia como palatina: «pour une tonalité franchement frivole ou burlesque ou grotesque ou boufonne, ou qu'on pournait encore dire "de farce" ou de "conte merveilleux" [... pour leur] nature hyperbolique» (Vitse, 1990: 324). No obstante, Oleza se muestra reacio a considerar que las comedias palatinas tengan que ser necesariamente de tono humorístico:

En todo caso el universo palatino no es ni unilateralmente cómico ni unilateralmente frívolo. Si muchas de las comedias palatinas hicieron de la fantasía un instrumento audaz — tanto como insolente - para explorar la corrupción y los crímenes del poder, las ambiciones y deseos ilegítimos de los tiranos, las pasiones adulterinas de reyes y grandes señores, las desigualdades de estado y linaje entre individuos o la vanidad e hipocresía de la vida cortesana, compartieron este instrumento con las tragedias y las tragicomedias palatinas, que exploraron esos mismo conflictos, pero desde una modalidad ejemplar y adoctrinante. No es seguro que las tragedias y tragicomedias fueran más allá, en esta exploración, de lo que fueron las comedias, posiblemente al contrario: el carácter ejemplar de los dramas impidió la libertad de movimientos, de imaginación y de crítica que se permitió, en grandes dosis, a la comedia, no a todas las comedias, es claro (Oleza, 1997: 251).

Las características que aquí hemos señalado son las principales que conforman el género conocido como comedia palatina, que podrían resumirse en una obra protagonizada por personajes ilustres enmarcados en espacios alejados 
de los hispanos. Sin embargo, no todas ellas cumplen con el propósito de este trabajo. Para ello, seleccionaremos tres de diferentes autores que incluyen entre sus dramatis personae damas bajo el nombre de Diana. A través de su análisis comprobaremos que todas presentan unas características comunes que remiten a la diosa mitológica, pues, según la tradición platónica pero también judeocristiana, «el nombre es como imagen de la cosa de quien se dice» (León, 1959: 398).

\section{De la diosa a la dama}

Diana es el nombre por el que se conoce a una divinidad sabina que no tardó en ser identificada con la diosa griega Artemisa, e incluso llegó a suplantar a Selene en el panteón mitológico, compartiendo rasgos, representaciones y mitos similares. Su primitivo carácter la califica como divinidad de la naturaleza, indómita y feroz. Es diosa de la caza y desprecia el amor, castigando con dureza y frialdad a quienes intentan retenerla, ya sea dios u hombre, por lo que es habitualmente tomada como representación de la doncella arisca que no se deja seducir, siendo incluso cruel. Sin embargo, ante las afiladas flechas de Cupido poco puede hacer y acabará posando sus ojos y su alma ante un humilde pastor de nombre Endimión. Por su faceta de cazadora es, además, un espíritu vengativo, que no descansa en la persecución y aniquilación de su presa. Por todo ello, fue nombrada protectora de las Amazonas, guerreras y cazadoras como ella e independientes del yugo del hombre.

Esta relación intertextual entre los nombres de los personajes de las comedias y su posible origen literario fue estudiada por Vitse (1988), confirmando así la multiplicidad de lecturas y niveles de interpretación que permiten las comedias del teatro del Siglo de Oro español. En muchos de los personajes llamados Diana creados por los dramaturgos auriseculares encontramos esta variedad de lecturas en su construcción. Estas mujeres se perciben como fuertes, desconocedoras del amor y frías ante los hombres que pretenden cortejarlas. El público, conocedor del trasfondo mitológico que goza el nombre de Diana, tendrá una imagen preconcebida de este personaje. La onomástica, sin lugar a duda, será un indicativo de la posición social a la que pertenece:

El tercer rasgo [de la comedia palatina] apunta hacia la particular onomástica de las protagonistas señoriales, que ha de estar acorde con su rango: abundan las Serafinas, Rosauras, Porcias, Teodoras, Madalenas, Auroras, Alejandras, Lisenas, Leonoras, Clemencias, Estelas, Isabelas, Sirenas, Clavelas... y los Fadriques, Enricos, Segismundos, Fisbertos, Arnestos, Mauricios, Rogerios, Prósperos, Otones..., nombres todos con ribetes altisonantes que se salen de lo cotidiano (Zugasti, 2003: 165). 
El nombre de Diana, al remitir a la divinidad, posicionará al personaje entre los estamentos más elevados de la sociedad. Como bien escribe García Ramón: «La onomástica personal refleja, en efecto, los valores sociales positivos (y también los negativos) de su colectividad, y, en general, la visión del mundo de sus hablantes» (2001: 105). Su comportamiento estará condicionado a ojos del espectador, quienes esperan encontrar a una mujer con un alto sentimiento de individualidad y de rechazo de la figura masculina, que intentará someterla a su poder. No obstante, antes de proseguir en nuestro análisis, debemos establecer una importante diferencia entre el género de la comedia donde esta figura esté presente. Las comedias mitológicas no basan su personaje en la divinidad latina, sino que es la propia diosa la que adquiere un protagonismo destacado en la acción. La Diana mitológica aparece no solo personificada sino también caracterizada como tal. Se basa en mitos clásicos, interpretaciones renacentistas e incluso libros de emblemas para reflejar ciertos adornos y caracterización sobre la escena que permitan identificarla sin dificultad. En El amor enamorado de Lope de Vega, por ejemplo, aparece Diana con «un perro al lado, como la pintan» (1999: v. 849aco.) y también «lleva una media luna en el tocado» (1999: v. 1.880aco.). En Celos aun del aire matan de Calderón de la Barca, aparece una acotación inicial donde indica que aparezca con un venablo, elemento del que más adelante hará uso, pero que ya señala a la diosa como la divinidad de la caza. Más adelante, se precisa su vestuario: «el [velillo] de Diana con estrellas de oro y el de las tres con algunas llamas de oro» (2002b: v. 1.448aco.). Por tanto, las Dianas que aparezcan en este tipo de comedias no son de interés para nuestro estudio, pues nuestra pretensión es ver el reflejo del personaje divino sobre los mundanos.

McKendrick (1974: 283-284) señala la figura mitológica como fuente para la construcción del modelo de la «mujer esquiva», a la que acceden los dramaturgos a través de la recuperación de los mitos clásicos durante el Renacimiento y las Metamorfosis de Ovidio. Esta tipología señalaría «the woman who [...] is averse to the idea of love and marriage. As a natural outcome, she is usually, but no invariably, averse to men as well» (McKendrick, 1974: 142). Y a su vez, se encarga de señalar que esta «esquivez» puede tener diversas manifestaciones, que pueden equipararse al carácter de la diosa cazadora, tal como hemos descrito antes:

In the plays the origin of the heroines' esquivez varies widely within the spectrum of vanity and pride. Some resent the idea of subjecting themselves to a man, others are so mannish that the very notion of love and marriage is anathema to them. Some think no man worthy of them, while for others to fall in love is folly for men and women alike (McKendrick, 1974: 282-283). 
No obstante, menciona otras diosas y criaturas mitológicas que pudieron haber influido en su caracterización como Atenea/Minerva, Dafne, Proserpina o las propias Amazonas, «who rebelled en masse against love and marriage and ejoyed the freedom of an all-female society» (McKendrick, 1974: 284). Diana diosa se convierte en el modelo de múltiples personajes femeninos en el teatro áureo y los propios dramaturgos así dan constancia en sus comedias:

$$
\begin{aligned}
& \text { No solo, pues, de Diana } \\
& \text { en la venatoria escuela } \\
& \text { discípula creció, pero } \\
& \text { aun en la altivez severa } \\
& \text { con que de Venus y Amor } \\
& \text { el blando yugo desprecia }
\end{aligned}
$$

(Calderón de la Barca, 2002a: vv. 289-294).

Debido a la complejidad de esta diosa, los dramaturgos abordan las distintas vertientes que presenta su carácter y agudizan o matizan las que puedan resultar de mayor interés a la hora de desarrollar sus personajes mortales en escena: «The combination of chastity and the chase as epitomized in her is one that recurs frequently in the drama. So also does the combination of a hatred of men and the chase associated with the Amazons» (McKendrick, 1974: 301).

Las Dianas mortales que encontraremos en las comedias palatinas del Siglo de Oro se fundamentarán en torno a dos puntos. Por un lado, estos personajes femeninos con un papel destacado pertenecerán a un estamento social elevado, como la nobleza o la realeza. Por otro, las características que definirán su carácter orbitarán siempre en torno a las propias de la diosa, comentadas con anterioridad. Si bien no siempre cumplirá con todas ellas, el dramaturgo potenciará aquellas que puedan interesar a favor del desarrollo de la trama. Los distintos autores dramáticos de la época cumplen con esta premisa, nombrando de esta manera a las protagonistas de carácter arisco que defienden su propia individualidad frente a los personajes masculinos que intentan imponer su dominio. A continuación, para demostrar nuestra hipótesis, analizaremos a las protagonistas de tres comedias palatinas de tres distintas plumas de nuestra literatura áurea.

\section{Diana en El celoso prudente de Tirso de Molina}

En la comedia El celoso prudente, el Mercedario nos presenta a la Diana, aparentemente, más distanciada de la imagen de la diosa mitológica. Si bien se muestra reacia y desdeñosa en su carácter para la pasión y el compromiso amoroso, siempre se encuentra dispuesta a obedecer las órdenes de las figuras de autoridad 
presentes en su vida. Por ello, sabe aceptar sin protestas un casamiento forzado que, en general, rechazan sus homónimas teatrales. Mediante este desacostumbrado comportamiento, no conforme al tópico de la mujer esquiva, Tirso subraya el sentido del honor y de la lealtad de Diana, su adhesión tanto a la voluntad de su padre como al amor de su esposo, lo que no carece de importancia para la continuación de la intriga y la consecución del enredo.

Diana es hija de Fisberto, un noble al servicio del rey de Bohemia, y hermana mayor de Lisena, a quien pretende ayudar en su enredo para lograr su matrimonio con el príncipe Sigismundo. Por ello, se ve abocada a un matrimonio con don Sancho, un noble español que comenzará a sospechar sobre el honor de su esposa, hasta el punto de plantearse acabar con ella. Por su disponibilidad noble y fiel, este personaje femenino presenta un carácter pasivo, provocando que se deje llevar por los acontecimientos que le rodean en favor de lograr la felicidad de su hermana. Es un personaje observador, con aplomo e inteligencia, pero sin iniciativa propia y subordinada a los valores del honor y de la familia.

Debido a estas características, es Diana la primera en ver que a su hermana le ocurre algo raro, y los sentimientos que la mueven a ello es la conjunción entre la responsabilidad fraternal y el honor para con la familia. Viendo que la relación no perjudicará a la familia, amablemente se muestra ante ella como amiga y se ofrece a ayudarla a conseguir su felicidad, aun a costa de la suya propia. Cuando Fisberto vuelve de improviso a su casa y descubre en el jardín a sus hijas con un desconocido que se da a la fuga, es la propia Diana quien deja que las culpas recaigan sobre ella, sintiéndose responsable en su papel de guardiana. Incluso cuando, durante el transcurso del tercer acto, oye a don Sancho planear su muerte, ni desmiente ni se excusa, cargando con el secreto para que Lisena logre su objetivo. Es, sin lugar a duda, un personaje fiel: fiel a su hermana, por quien está dispuesta a llevar una mancha en su honor por un delito que no ha cometido; y fiel a su marido, don Sancho. Fiel es así también a su honor y al honor familiar, tanto aquella en la que nació, y con la que comparte un vínculo sanguíneo, como aquella a la que se incorpora mediante el matrimonio con el noble español.

Diana se muestra al principio de la comedia con un comportamiento rígido y duro, sobre todo hacia el amor y los personajes masculinos, asemejándose, tal como su hermana señala, a Anajarte:

LisenA Y que cuantos quieren bien, una Anajarte alemana en tu severidad ven, siendo en el nombre Diana

(Tirso, 1946: vv. 131-134). 
No obstante, tras su matrimonio con don Sancho y el trato que este le dispensa, su dureza se irá ablandando y en su interior despertarán sentimientos verdaderos hacia su persona. Como señala Redondo: «Tirso de Molina, paralelamente a los ingenios contemporáneos, juega pues con los elementos antroponímicos, pero también con las reglas impuestas por la comedia acerca de las actuaciones que corresponden a cada cual, según su estatus social» (2005: 1.310).

Diana, por su conexión con Lisena y con don Sancho, y por haber permitido ser inculpada, se convierte en el personaje central sobre el que orbitan las tramas de la comedia. Todas las malinterpretaciones y malentendidos giran en torno a su figura. Dejándose culpar por su hermana y permitiendo que ella haga uso de su nombre en escenas posteriores, irá plantando las semillas de la duda en los personajes de poder como el rey, su padre o su propio marido. Se convierte, por tanto, en el punto de enlace en el que convergen dos acciones tan dispares, una amorosa, otra acerca del honor:

Don Sancho's fear for his honor are balanced by Lisena and Prince Sigismundo's desire to marry. These two themes are linked through Diana, Lisena's sister and Sancho's wife Her position as connector binds the two elements of the plot together and places her as the pivot point for both halves (Turner, 2006: 99).

Tanto si fracasa la traza de su hermana y Alberto, como si don Sancho lleva a cabo su terrible plan, la muerte de Diana se presenta como segura.

Dentro de la esfera social, Diana es un personaje que goza de gran libertad de movimiento, igual que la diosa recorría los bosques. El matrimonio al que se ve forzada se da porque se ha producido una situación que ha escapado de su control: el honor de su familia está en juego y es la única manera en que puede salvarlo $\mathrm{y}$, al mismo tiempo, cumplir con sus obligaciones como hermana mayor. Hasta el momento, nadie ha obligado a Diana a pasar por el altar, disfrutando del poder de la decisión. Cuando su padre descubre a las hermanas de noche en el jardín, duda de la explicación dada por su primogénita, quien, libremente, propone su ingreso en un monasterio:

\section{Diana ¿Eso se ha de imaginar de mí? Ireme a un monasterio, y podraste asegurar}

(Tirso, 1946: vv. 867-869).

Podríamos pensar que esta decisión se debe a las restrictivas normas que regían una sociedad patriarcal, cuando se trata de una decisión tomada libremente. No hay que olvidar que las posibilidades de la mujer durante el siglo XVII eran limitadas: 
Exceptuando a las nobles que tenían la vida resuelta económicamente y a la villana, cuyo lote no era muy diferente del de otras campesinas en el mundo, no había muchas sendas que la mujer pudiera seguir en aquel tiempo fuera del matrimonio. Su abanico de posibilidades incluía: recluirse en un convento, darse a la mala vida, ponerse al servicio de alguna gran dama, o la vida en familia (Hernández García, 1998: 79).

Diana es quien decide, libremente, cargar con las acusaciones de su hermana, pudiéndose negar. Es quien permite que Lisena use su nombre para comunicarse con Sigismundo, aun conociendo los peligros que puede entrañar esta decisión. Por tanto, la libertad de la que goza es lo que le permite ofrecerse como «sacrificio» para el bien de su familia, ya que al cargar con la «culpa» permite salvar tanto a su hermana como a su marido.

Pese a que es su hermana quien le acusa de ser la dueña del papel y el retrato, ella acepta sin queja el delito, salvándola y permitiendo que pueda llevar a cabo su plan para lograr el matrimonio con Sigismundo. De igual modo, debido a que don Sancho cree que su honor está en riesgo, la muerte de Diana serviría para sanarlo, sirviendo así de sacrificio. Aunque finalmente no llega a ocurrir, la tragedia planea durante dos terceras partes de la comedia. Se inserta, por tanto, en el ideal cristiano del sacrificio por un bien mayor, ya que es consciente que, de las dos, su hermana es la que más tiene que ganar en esta situación.

\section{Diana en EL PERRo DEL hortelano DE Lope DE Vega}

Este caso posiblemente presente el carácter más humano al tiempo que el más distante con sus semejantes. Desde el pedestal en que se encuentra, gracias a su posición social, observa inmutable las proposiciones que sus pretendientes le hacen, sin éxito alguno. No será hasta que presencie la relación entre Teodoro y Marcela que los celos aflorarán, provocando en su persona sentimientos encontrados, desestabilizando su semblante distante y altivo, cuasi divino. La dama protagonista de esta comedia, al igual que sus homónimas, adquiere en su construcción diversos rasgos de su contraparte divina. Su gran belleza, que atrae a multitud de hombres a sus puertas, así como su rechazo sistemático al amor o a cualquier vínculo afectivo que coarten su libertad, se convierten en sus rasgos más destacados, referenciados por diversos personajes a lo largo de la comedia:

\footnotetext{
OTAVIO ¿Nadie en Nápoles te quiere

que, mientras casarse espere, por donde puede te ve?

¿No hay mil señores que están, para casarse contigo, ciegos de amor? [...]
} 


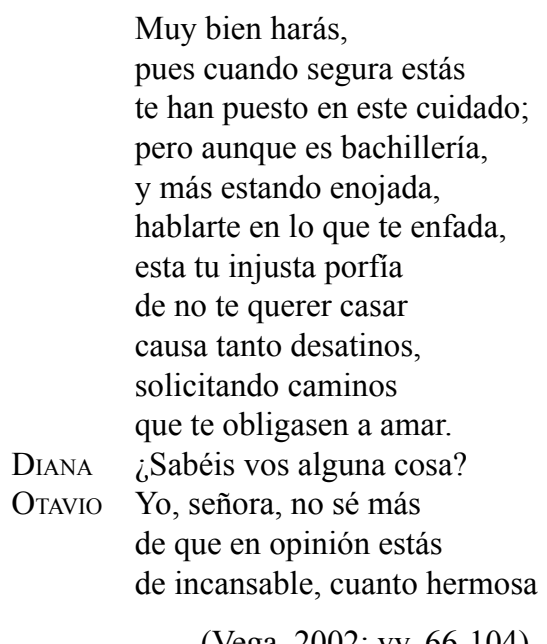

(Vega, 2002: vv. 66-104).

Al igual que ocurre en los casos anteriores, para reforzar la asimilación con su divino referente grecorromano, los personajes de la comedia comparan a la dama con distintos personajes o situaciones mitológicas. Esta técnica refuerza la construcción interna del personaje a ojos del espectador, al tiempo que tiene la función de recoger los precedentes clásicos de los que el autor hace uso, no tan solo como fuente del personaje, sino de todo su universo dramático. De este modo, Anarda, su criada, reprehendiendo su actitud ante los hombres, la compara con dos figuras femeninas que aportan unas características definitorias a su carácter, que comparte con el resto de casos presentados:

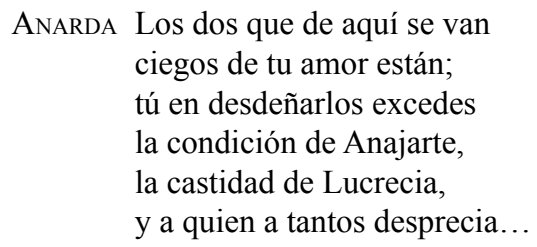

(Vega, 2002: vv. 1.593-1.558).

La comparación con mujeres como Anajarte o Lucrecia refuerza la construcción del personaje durante la segunda jornada de la comedia, caracterizando a Diana como una mujer fría y distante con los hombres, de espíritu duro e impertérrito frente al sentimiento amoroso, así como casta y mujer de entereza, capaz de morir antes que ser deshonrada. Marcela, por su parte, en la primera jornada de la comedia, relaciona a la dama con la luna, atributo de Selene que, más tarde, adquiriría Diana: 


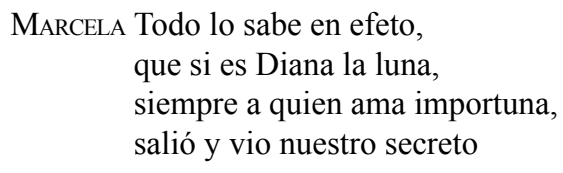

(Vega, 2002: vv. 911-914).

No podemos dejar de lado un rasgo principal de la Diana diosa y es su faceta como protectora de la caza. En el caso de esta comedia, la condesa parece emprender una batida incesante contra su secretario Teodoro, en un juego de constante persecución, cansándolo y liberándolo cada vez que ve cercana la consecución de sus intenciones. A diferencia de otras comedias de enredo en las que es el galán quien emprende una persecución, a veces física, a veces verbal, hacia su objeto de deseo, en esta comedia de Lope de Vega no es Teodoro quien pone los ojos en Diana, sino la condesa en él, espoleada por la saeta de los celos. La imposibilidad de que la unión entre ambos se lleve a cabo por razones sociales, no impide a la dama tener a su secretario en su punto de mira, como un desafío imposible que debe perseguir impulsada por su deseo.

La fortaleza de Diana se vislumbra también en sus relaciones sociales dentro de la comedia. Se trata de una mujer que no se encuentra sometida a ninguna jerarquía superior y masculina, al menos dentro de los parámetros que establece el texto. En comparación con el resto de personajes, se sitúa en la cima de la pirámide del poder, estando el resto subordinados a ella, incluso los varones. La inclusión de un padre o un hermano en el reparto hubiera arruinado la inconsistencia en la toma de decisiones de Diana, característica propia que define, además, la singularidad de la trama y el título de la comedia.

\section{Diana en El desDÉn con el DESDÉn de Agustín Moreto}

Este último caso es considerado como «uno de los ejemplos más conocidos de la mujer esquiva en el teatro español del Siglo de Oro» (Castells, 2010: 205). Presenta una actitud cínica frente al amor, que ha adquirido a través de sus estudios en filosofía e historia, los cuales le han demostrado que este sentimiento solo produce en los amantes «ruinas y destrozos, / tragedias y desconciertos» (Moreto, 1999: vv. 837-838). Diana, pese a su actitud arisca e independiente, no aleja a los hombres, sino más bien supone un atractivo foco en el que centran sus atenciones. A un lado tendríamos que dejar el interés que pueden suscitar estas pretensiones de matrimonio, pues no queda claro si la atracción se debe únicamente a la belleza de la dama o si también están involucrados intereses políticos, ya que no hay que olvidar que su padre es conde de Barcelona. Su decisión de no casarse radica en su creencia, teórica, de que el matrimonio supone la muerte intelectual y espiritual de las personas. 
Respecto a la inteligencia y sabiduría que, aparentemente, caracterizan a este personaje y la posicionan contraria a la unión entre hombre y mujer, debemos atender a las razones que diversos investigadores, como Castells (2010), han presentado. Los extensos conocimientos de Diana acerca de materias diversas pueden sorprender y asombrar al iletrado, pero, prestando atención a su discurso, no tardamos en encontrar una carencia de conocimientos básicos en materias como la geografía o el latín. Por eso, su encuentro con Carlos, quien no se deja intimidar o desarmar fácilmente por sus alambicadas disertaciones, produce en la protagonista un fuerte conflicto social e íntimo, pues sucede un cambio en su consideración de mujer sabia a ignorante.

Estos conocimientos le sirven como escudo tras el que protegerse del destino que su padre quiere imponerle bajo la forma de bodas y pretendientes, negándole el libre albedrío. Su oposición a casarse con alguien que, bajo su consideración, sea inferior a ella, demuestra su autodeterminación a la par que rebeldía frente a las figuras de autoridad. Sin embargo, su actitud, propia del modelo de la «mujer esquiva», acabará relajándose y acabará casándose con Carlos, por propia decisión, manteniéndose firme en sus propósitos. Pudiendo haber dejado que el galán se casara con su criada Cintia, es a través de su propia voz que decide su destino, al tiempo que cumple con la petición paterna de casarse:

En el primer acto Diana indica que ha llegado a estas conclusiones después de largos años de estudio, aunque también sugiere que esta actitud es una parte natural de su carácter. Esta postura contradictoria sugiere que pudiera estar confundida sobre el origen de su desdén, pero sus discusiones con Carlos indican que su postura es solo el resultado de su preferencia personal (Castells, 2010: 212).

Para terminar de cumplir con la identificación entre este personaje y la diosa en la que se inspira, a lo largo de la comedia aparecen multitud de aspectos mitológicos de manera recurrente que ayudan a perfilar el retrato de la protagonista:

Hasta el nombre de esta mujer desdeñosa remite a la Diana casta de la mitología [...] Los ecos mitológicos acogen también el nombre de sus criadas: Laura - laurel, Dafne - y Cintia — advocación de Diana, a la que se veneraba en el monte Cintio- y todo el ambiente y las resonancias mitológicas son en esta comedia mucho más que meros ornamentos prescindibles (Lobato, 2008: 405).

Los distintos personajes que se relacionan con la dama se refieren, en diversas ocasiones, a escenas y mitos relacionados con la diosa que ayudan a pintar e identificar al personaje con su fuente más directa, así como las características: 
A su cuarto hace la selva de Diana, y son las ninfas sus damas, y en este estudio las emplea todo el día. Solo adornan sus paredes de las ninfas fugitivas pinturas que persuaden al desdén: allí se mira a Dafne huyendo de Apolo; Anaxarte, convertida en piedra, por no querer; Aretusa, en fuentecilla que al tierno llanto de Alfeo paga en lágrimas esquivas

(Moreto, 1999: vv. 195-208).

El nombre o las referencias mitológicas mencionadas son tan solo la base en la que se asienta la asimilación entre la diosa y la dama. La Diana de esta comedia, así como la de El perro del hortelano, reflejan también en su carácter la vertiente cazadora, omitida en el caso de El celoso prudente. El ser rechazada por Carlos, primera vez que le ocurre, despierta en la dama el deseo de superar ese obstáculo que se le ha presentado, un desafío autoimpuesto por su propia naturaleza. Para ello, perseguirá al caballero, compitiendo con él, sobre todo desde lo intelectual, hasta lograr vencerlo, sometiéndolo e imponiéndose. Diana logra la victoria a través del matrimonio, arrebatándoselo a su criada Cintia, y alzándose, por tanto, con una doble victoria. La protagonista encarna de este modo la esencia de la diosa cazadora, implacable en su batida, provocada por el mismo desdén del que ella hace gala con sus pretendientes:

To begin with, the efficacy of disdain has already been proved to his chagrin by Carlos, who has fallen in love with Diana in spite of her 'hermosura modesta / con muchas señas de tibia' (Act I, BAE XXXIX, I) because for the first time in his life he is unable to take what he wants just for the asking. He is not slow to realize that only the challenge which the unattainable represents for his own egoism will succeed in shaking Diana's, and he therefore poses as an hombre esquivo, daring Diana to try to reduce him to the same state of object submission as her other suitors. Diana swallows the bait: 'He de hacer empeño / de rendir su vanidad' (Act I, BAE XXXIX, 6c), little realizing that with these words she is passing judgement, not on Carlos' motive, but her own (McKendrick, 1974: 149). 


\section{LA DAMA FRENTE A LA DIOSA: CONTRAVINIENDO LA FIGURA MITOLÓGICA}

Con todo lo expuesto hasta el momento, podemos comprobar cómo los personajes femeninos de la comedia palatina nombrados «Diana» comparten unas características comunes, al provenir de manera directa de la divinidad homónima grecorromana. Sin embargo, existe un aspecto que contraviene la libertad e individualidad que la diosa goza: el matrimonio. Todas las Dianas dramáticas, sin excepción, acaban finalmente casadas, pese a las muestras de frialdad, dureza y rechazo hacia esta unión y, más concretamente, hacia la figura masculina y el poder que este ejerce sobre ellas. Por tanto, ¿por qué motivo acaban casadas, contraviniendo el referente mitológico?

La respuesta la encontramos en el orden natural y social que regía la Europa del siglo XVII, que reside en la responsabilidad de los individuos de casarse y tener descendencia, respaldándose en motivos humanos y políticos:

Las normas contemporáneas consideran que la postura de la mujer esquiva sobre el matrimonio y las relaciones humanas representa una rebelión inaceptable en contra de las leyes naturales. Como resultado de esta contradicción, al final de estas obras la mujer esquiva típicamente se enamora del protagonista y acepta su papel natural como esposa y futura madre (Castells, 2010: 206-207).

Tal como se encarga de señalar McKendrick: «any evasion or denial of love is a revolt against Nature itself» (1974: 149). Los textos dramáticos cumplen una función moralizadora, a través de los que se transmiten enseñanzas al público, iletrado o no, que asistía a las representaciones ${ }^{5}$. Pese a mostrar, como en el caso de las comedias aquí analizadas, a una mujer rebelde sobre las tablas, la trama presentada no podía acabar sin un cambio en el comportamiento de este personaje, respondiendo a las leyes naturales imperantes de la época. Así el matrimonio se contempla como el destino necesario, imperante e ineludible de las damas, que se refuerza a través de los versos recitados en los corrales. Esta relación entre matrimonio y ley natural se hace explícita de manera directa en las propias comedias, para que personajes y público sean conscientes de ello:

¡Que por error su agudeza quiera el amor condenar; y si lo es, quiera enmendar lo que erró naturaleza!

(Moreto, 1999: vv. 555-558).

$5 \quad$ No debemos olvidar la máxima docere et delectare que tan amplia difusión tuvo entre los dramaturgos del Siglo de Oro español. Tirso de Molina tituló incluso de este modo su segunda miscelánea, Deleitar aprovechando, publicada en 1632. 
Este orden natural no es solamente aplicable a las mujeres. Los hombres también debían responder ante el mismo, y no pueden escapar de él: «For the Golden Age the natural forces in man were as powerful as those in woman and he was as subject to love as she» (McKendrick, 1974: 151). No obstante, es cierto que un personaje rebelde femenino suscitaba un mayor impacto entre el público, ya que normalmente solía encontrarse siempre sometido a una figura de autoridad masculina. Al no ser habitual que gozara de independencia e individualidad, esta situación gozaba de mayor atractivo para el público que presenciara la comedia.

\section{Conclusiones}

En las producciones del Barroco español, el antropónimo no funciona tan solo como un identificador individual, sino también como una marca que contiene información definitoria acerca de quien lo porta. Este sistema de «nombres parlantes», cuyo origen se remonta a Plauto, es compartido por todos los dramaturgos y escritores de la época, permitiendo la creación de un cosmos de antropónimos cuyo significado, etimología o vinculación con un referente clásico conocido ayuda a la caracterización del personaje al que designan.

Los nombres propios de los personajes poseen un valor semiótico y semántico específico y un potencial significativo o de intervención en el interior del campo literario en el que aparecen. Como indica Ionescu:

El estudio de la onomástica literaria no puede prescindir del aspecto semántico y debe proponerse descubrir las funciones y los valores literarios de los nombres ficticios, o sea, explicar de qué manera y en qué medida estos contribuyen a la construcción del significado global de una obra determinada (1993: 306).

Sin embargo, siempre deben estar supeditados a las características propias del género y la época en que tienen lugar, ya que su aportación puede dar lugar a una lectura propia o encauzada que puede divergir del referente tradicional.

Por tanto, el nombre de Diana, en el contexto de la comedia palatina, tendrá la función principal de caracterizar al personaje. En su esencia, poseerá una serie de particularidades que nos remitirán, a grandes rasgos, a la diosa grecolatina homónima: será un personaje independiente, que rechaza cualquier tipo de unión, fría y distante con los hombres y que pertenece a un estado elevado de la sociedad. No obstante, cada uno de los casos tendrá una serie de remotivaciones que, sin alejarse de los rasgos distintivos ya expuestos, permitirán perfilar al 
personaje en función de la finalidad de la comedia y el contexto en el que el dramaturgo lo enmarque, individualizando y dotándolo de un valor particular. Es por este motivo que, aparentemente, estas damas acaben casándose, cumpliendo la ley natural y alejándose, por tanto, del destino solitario que se impone la deidad virgen de la caza.

\section{BIBLIOGRAFÍA}

Alonso de SANTos, José Luis (2012). Manual de teoría y práctica teatral. Barcelona: Castalia.

Arellano, Ignacio (1986). «Semiótica y antroponimia literaria». En Investigaciones semióticas I. Madrid: Consejo Superior de Investigaciones Científicas, pp. 53-66.

Aristóteles (1988). Poética. Valentín García Yebra (trad.). Madrid: Gredos.

Bances Candamo, Francisco (1970). Teatro de los teatros de los pasados y presentes siglos. Duncan W. Moir (ed.). London: Tamesis Books.

Barthes, Roland (1967). «Proust et les noms». To Honor Roman Jakobson. The Hague and Paris: Mouton, t. I, pp. 150-158.

BÉZIAT, Florence (1996). «Sobre algunos aspectos del silencio en cuatro comedias palatinas de Tirso de Molina». Scriptura, 11, pp. 43-62.

Calderón de la Barca, Pedro (2002a). Afectos de odio y amor. Alicante: Biblioteca Virtual Miguel de Cervantes <http://www.cervantesvirtual.com/obra/afectos-de-odio-yamor--0/> [Consulta: 16/05/2019].

Calderón de la Barca, Pedro (2002b). Celos aun del aire matan. Alicante: Biblioteca Virtual Miguel de Cervantes <http://www.cervantesvirtual.com/obra/celos-aun-delaire-matan--0/> [Consulta: 16/05/2019].

CASTElls, Ricardo (2010). «El papel contradictorio de la mujer esquiva en El desdén, con el desdén de Agustín Moreto». En Aurelio González, Serafín González y Lillian von der Walde Moheno (eds.), Cuatro triunfos áureos y otros dramaturgos del Siglo de Oro. Ciudad de México: Colegio de México, pp. 205-215.

García RAMÓN, José Luis (2001). «Onomástica y cultura clásica». Estudios Clásicos, 120, pp. 105-118.

Hernández García, Carmela (1998). Fondo y forma del teatro del siglo de oro. Madrid: La Avispa.

HoEk, Leo (1981). La marque du titre. Berlin: DeGruyter.

IONESCU, Christian (1993). «Onomástica literaria: dominio interdisciplinar». Butlletí de la Societat d'Onomástica, 54-55, pp. 305-315.

León, Luis de (1959). Obras completas. Félix García (ed.). Madrid: Biblioteca de Autores Cristianos.

Lobato, María Luisa (ed.) (2008). El desdén con el desdén. En Agustín Moreto, Primera parte de comedias, I. La fuerza de la ley. El mejor amigo, el rey. El desdén con el desdén. Kassel: Reichenberger.

LÓPEZ LóPEZ, Matías (1989). «La relación “nombre/cosa”: el ejemplo de los personajes plautinos». Faventia, 11, pp. 5-18. 
McKendrick, Melveena (1974). Woman and Society in the Spanish Drama of the Golden Age: A Study of the Mujer varonil. London: Cambridge University Press.

Meunier, Philippe (1995). Stratégies onomastiques et poétiques dans le théâtre de Tirso de Molina. Nadine Ly (dir.) [tesis doctoral]. Bordeaux: Université Bordeaux III.

Meunier, Philippe (2015). «Tirso de Molina y la poética del nombre». En Blanca Oteiza (ed.), Prosas y versos de Tirso de Molina. Madrid / Pamplona / New York: Instituto de Estudios Tirsianos / Instituto de Estudios Auriseculares.

Mill, John Stuart (2002). A System of Logic. Honolulu: University Press of the Pacific.

Moreto, Agustín (1999). El desdén con el desdén. Alicante: Biblioteca Virtual Miguel de Cervantes <http://www.cervantesvirtual.com/obra/el-desden-con-el-desden--0/> [Consulta: 16/05/2019].

Moreto, Agustín (2008). Primera parte de comedias, I. La fuerza de la ley. El mejor amigo, el rey. El desdén con el desdén. Miguel Zugasti, Esther Borrego Gutiérrez, Beata Baczy'nska y María Luisa Lobato (eds.). Kassel: Reichenberger.

Morley, Sylvanus Griswold (1959). "Character Names in Tirso de Molina». Hispanic Review, 27, 2, pp. 222-227.

Morley, Sylvanus Griswold y Richard W. TyLER (1961). Los nombres de personajes en las comedias de Lope de Vega. Madrid: Castalia.

OlezA, Joan (1997). «La comedia y la tragedia palatina: modalidades del arte nuevo». Edad de Oro, 16, pp. 235-252.

REDONDO, Agustín (2005). «Reescritura de la historia y problemas textuales, antroponimia y dramatización de los conflictos en la comedia de Tirso de Molina, Cómo han de ser los amigos». En Pedro Manuel Piñero Ramírez (coord.), Dejar hablar a los textos: Homenaje a Francisco Márquez Villanueva. Sevilla: Universidad de Sevilla, pp. 1.297-1.316.

Tirso de Molina (1946). El celoso prudente. En Blanca de los Ríos (ed.), Obras dramáticas completas. Madrid: Aguilar.

Turner, Robert (2006). Disguise, Identity and Female Cross-Dressing in Selected Works of Tirso de Molina. Nashville: Vanderbilt University.

Vega, Lope de (1999). El amor enamorado. Alicante: Biblioteca Virtual Miguel de Cervantes <http://www.cervantesvirtual.com/obra/el-amor-enamorado--0/> [Consulta: $16 / 05 / 2019]$.

VEGA, Lope de (2002). El perro del hortelano. Alicante: Biblioteca Virtual Miguel de Cervantes $<$ http://www.cervantesvirtual.com/obra/el-perro-del-hortelano--0/> [Consulta: $16 / 05 / 2019]$.

VITSE, Marc (1988). Eléments pour une théorie du théâtre espagnol du XVII siècle. Toulouse: Université de Toulouse-Le Mirail.

WARDROPPER, Bruce (1978). «La comedia española del Siglo de Oro». En Elder Olson (ed.), Teoría de la comedia. Barcelona: Ariel, pp. 181-242.

WeBer, Frida (1975). «El perro del hortelano, comedia palatina». Nueva Revista de Filología Hispánica, 24, pp. 339-363.

Weber, Frida (1977). «Hacia una sistematización de los tipos de comedia de Lope de Vega». En François López, Joseph Pérez, Noël Salmon, Maxime Chevalier (coords.), Actas del quinto congreso internacional de hispanistas. Bordeaux: Université de Bordeaux, pp. 867-871. 
Zugasti, Miguel (2003). «Comedia palatina cómica y comedia palatina seria en el Siglo de Oro». En Eva Galar y Blanca Oteiza (coords.), El sustento de los discretos. La dramaturgia áulica de Tirso de Molina. Actas del Congreso Internacional organizado por GRISO (Monasterio de Poyo, Pontevedra, 4-6 de junio de 2003). Pamplona: Instituto de Estudios Tirsianos, pp. 159-185.

Recibido: $23 / 05 / 2019$

Aceptado: 20/12/2019 


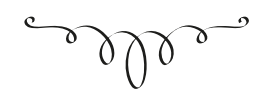

DiANA EN PALACIO: EL NOMBRE COMO FORJADOR DE UN DESTINO

RESUMEN: El presente estudio se propone analizar si el nombre influye en la construcción del personaje en las producciones dramáticas del Siglo de Oro, así como si su destino en la trama está predestinado por él. Debido a la gran cantidad de personajes y la amplia variedad en cuanto a tipología de textos teatrales, centraremos nuestra atención en el uso que dan del nombre de Diana en las obras de un grupo reducido de autores (Lope de Vega, Tirso de Molina y Agustín Moreto) dentro de la conocida como comedia palatina, y cómo remite a la diosa grecolatina homónima.

Palabras clave: Onomástica, Tirso de Molina, Agustín Moreto, Lope de Vega, teatro del Siglo de Oro, comedia palatina.

\section{Diana In THE PALACE: THE NAME AS CREATOR OF A FATE}

AвSTRACT: The present study intends to analyze whether the name influences the construction of the character in the dramatic productions of the Spanish Golden Age as well as how her fate in the plot is predestined by it. Due to the large number of characters and the wide variety of types of theatrical texts, we will focus our attention on the name of Diana in the plays of a small group of authors (Lope de Vega, Tirso de Molina and Agustín Moreto) within the comedy known as palatine, and how it refers to the homonymous Greco-Roman goddess.

KeYwords: Onomastics, Tirso de Molina, Agustin Moreto, Lope de Vega, Spanish Golden Century Theater, Palatine Comedy. 